\title{
O SUS necessário e o SUS possível: estratégias de gestão. Uma reflexão a partir de uma experiência concreta
}

\author{
The needed Brazilian Health System and the possible \\ Brazilian H ealth System: management strategies. \\ An experience-based reflection
}

Luis Eugenio Portela Fernandes de Souza ${ }^{1}$

IInstituto deSaúde Coletiva, Universidade Federal daBahia.

Rua Basílio da Gama, s/n, Campus do Canela. 40110-040 Salvador BA. luiseugenio@ufba.br
Abstract Thepresent text presents a reflection about the author's experience as head of a Health Department of a big city during two and a half years. It presents a systematization of the strategic projects, the political and technical activities and the managerial routine, in which he was involved. It identifies three levels (macro, meso and micro) and four dimensions of management (social-political, institutional, technical-sanitary and administrative in the strict sense). In each dimension, on the three levels, it discusses management strategies desi gned to contribute to the construction of a universal and equitable Brazilian Health System (SUS). Although it may be premature to evaluate the degree of implantation and the effects of the proposed strategies, their analysis and discussion can be useful for being strongly based on empirical elements. The paper concludes that, even though the consolidation of the SUS is a political struggle that surpasses the management arena, managers are important agents who need to know how to develop strategies able to foster the principles of universality and equity.

Key words Healthcare management, Healthcare manager, Brazilian H ealth System
Resumo 0 presente texto constitui uma reflexão sobre a experiência do autor como gestor de uma secretaria de saúde de um município de grande porte, durante dois anos e meio. Apresenta uma sistematização dos projetos estratégicos, das atividades políticas e técnicas e da rotina gerencial em que se envolveu enquanto gestor. Parte da identificação de três níveis (macro, meso e micro) e de quatro dimensões da gestão ( sociopolítica, institucional, técnico-sanitária e administrativa senso estrito). Em cada dimensão, nos três níveis, são discutidas estratégias degestão, propostas para contribuir com a construção de um SU S efetivamente universal e eqüitativo. Ainda que seja prematuro avaliar o grau de implantação e os efeitos das estratégias propostas, a sua discussão pode ser útil na medida em que adota um quadro de análise das práticas de gestão fortemente baseado em elementos empíricos. Conclui-se que, embora a consolidação do SU S seja uma luta política que extrapola o espaço da gestão, os gestores são agentes importantes que precisam saber desenvolver estratégias consistentes com os princípios da universalidadee da equidade.

Palavras-chave Gestão em saúde, Gestor de saúde, SUS 
Introdução

A implantação do SUS requer uma sociedade em que todos os cidadãos tenham assegurado um padrão de vida digno. É difícil se pensar em um sistema desaúdeuniversal e eqüitativo em um país, como o Brasil, onde a muitos faltam condições de sobrevivência.

Todavia, se é difícil ter o SUS legal cabalmente implantado nas atuais condições sociais do país, não é menos difícil reverter esse quadro sem uma política de saúde baseada nos princípios de universalidade e equidade. Na verdade, o SUS é uma estratégia das mais importantes para a construção de um país socialmente justo.

N esse sentido, o SUS necessário, para que tenhamos uma sociedade mais justa, está definido nos seus princípios legais. Por sua vez, o SU S possível hojeéaquelequeseencontra no funcionamento cotidiano dos serviços de saúde. A pesar dos significativos avanços desde o início dos anos noventa, o SUS possível ainda está longe do SUS necessário.

As estratégias para aproximá-los são eminentemente políticas. Têm a ver com a luta pelo poder entre, deum lado, os beneficiários do statu quoe, de outro, aqueles que podem melhorar suas condições de vida com o funcionamento efetivo do SUS.

$N$ a realidade brasileira, há uma maioria de pessoas pobres que depende do SUS para ter acesso aos serviços de saúde e, portanto, ao menos em tese, se interessa pela efetivação completa do seu ideário.

Há, em oposição à maioria, grupos que auferem benefícios com as dificuldades do SUS: muitos dos que têm negócios no setor privado da saúde, inclusive os que vendem insumos para serviços de saúde, e aqueles que se opõem a maiores investimentos públicos - em saúde ou em qualquer área - que representem um risco de menor remuneração do capital financeiro.

Pode-se ainda identificar um terceiro contingente de pessoas com níveis de renda alto ou médio que, tendo resolvido sem o SUS parte dos seus problemas de acesso aos serviços de saúde, não se mobilizam pela sua melhoria.

A luta política, como é de sua natureza, se desenrola nos mais diversos planos da vida social. No caso da saúde, as diferentes propostas de organização da atenção são objetos de disputa nos planosideológico, econômico einstitucional.

No plano institucional, a gestão de organizações públicas de saúde é uma relevante arena de disputa entre os defensores e opositores do SUS. E não poderia ser de outro modo: as instituições de saúde representam espaços de exercício de poder.
Para refletir sobre estratégias de gestão que aproximem o SUS possível do SUS necessário, deve-se, portanto, em primeiro lugar, compreender a implantação do SU S como uma luta política.

Em segundo lugar, é útil adotar um conceito amplo de gestão, pois é abrangente o escopo do SUS e, por conseguinte, das atividades do gestor da saúde. Pode-sedistinguir, seguindo Garcial' uma macrogestão, referida às ações de formulação de políticas; uma mesogestão, relacionada às atividades de condução de uma organização; e uma microgestão, atinente à coordenação dos processos de trabalho desenvolvidos em uma organização.

Por último, devese considerar os três níveis de gestão nas diferentes dimensões da administração da saúde. As dimensões correspondem a atividadesfins queo gestor éobrigado a desenvolver para cumprir seu papel de dirigente. A partir de nossa experiência prática, classificamos as dimensões em quatro grupos, relativos a quatro objetivos de gestão:

1) Sustentação social do projeto político do SUS;

2) Viabilização institucional do projeto político;

3) Fortalecimento da condução técnica da organização de saúde;

4) Garantia da coordenação administrativa da organização.

\section{A dimensão sociopolítica}

A dimensão sociopolítica contempla as ações voltadas para obter o apoio da população às políticas do SUS. Se, em tese, a maioria da população tende a apoiar a efetivação do SUS, na prática é preciso que as pessoas percebam os benefícios que o SUS traz para que se mobilizem em sua defesa.

É certo que houve, nos últimos dezessete anos, uma expansão significativa de serviços. Contudo, persistem dificuldades de acesso motivadas pela baixa oferta, assim como há problemas de qualidadetécnica. Por isso, a estratégia fundamental para aproximar o SUS possível do SU S necessário, conquistando o apoio da população, é expandir e melhorar a qualidade dos serviços de saúde.

Outra importante estratégia se refere à participação popular. Sendo o SUS um projeto democratizante, o gestor não pode negligenciar as ações que visam ao fortalecimento da participação de usuários, trabal hadores da saúde e prestadores de serviços na definição e no acompanhamento das políticas de saúde. A abertura de canais institucionais de participação permite que os interessados no sucesso do SU Sinfluenciem as decisões governamentais.

Para viabilizar essas estratégias, ações nos três níveis de gestão são necessárias. 
No nível macro, é preciso tomar, de forma inequívoca, a decisão de alocar recursos suficientes para a expansão e a qualificação dos serviços e para apoiar a participação.

$\mathrm{Na}$ nossa experiência, optamos por expandir e qualificar os serviços em duas frentes: a atenção básica, através do Programa de Saúde da Família (PSF), ea aten ção às urgências, a partir da implantação do Serviço deAtendimento M óvel deUrgência (Samu). Asseguramos recursos da ordem de $\mathrm{R} \$ 60$ milhões (cerca de $25 \%$ do orçamento anual da Secretaria Municipal da Saúde - SM S) para o PSF, prevendo dobrar o número de equipes só no primeiro ano de gestão. Para o Samu, foram garantidos cerca de 24 milhões (10\% do orçamento). No que concerne à participação, foram previstos recursos suficientes para a implantação de ConseIhos Locais em todas as Unidades de Saúde, para a realização das Conferências de Saúde e para a capacitação de conselheiros.

No nível meso, é preciso comandar os diversos setores da instituição - áreas técnicas, setor administrativo, setor financeiro, etc. - para executarem as ações correspondentes à decisão de expandir e melhorar os serviços. No caso da participação popular, a organização como um todo deve incorporá-la como uma diretriz permanente, o que pode exigir a criação de instâncias internas específicas para apoiar a participação.

$\mathrm{Na}$ prática, implantamos duas forças-tarefa, diretamente subordinadas ao Gabinete do Secretário, com a participação de técnicos da Coordenação de Atenção ePromoção da Saúde, da Coordenação Administrativa e da Coordenação de De senvolvimento de Recursos Humanos, para conduzir as atividades relativas à expansão do PSF eà implantação do Samu. Criamos também uma Assessoria Especial de Gestão Participativa, que se incumbiu de coordenar o processo de apoio à participação popular.

No nível micro, o gestor tem que desencadear e acompanhar os processos de trabal ho referentes às ações de expansão emel horia dos serviços: o planejamento e a programação, a elaboração de normas e rotinas técnicas, a contratação de empresas de fornecedores de materiais, a al ocação e capacitação dos trabalhadores e a dotação de recursos financeiros. 0 fortalecimento da participação, por sua vez, requer que os vários setores da instituição aprendam a contemplá-la nos seus processos de trabaIho. Por exemplo, o setor de pessoal tem que funcionar rotineiramente com a mesa permanente de negociação com os trabalhadores da saúde.

$\mathrm{Na}$ nossa rotina, as atividades relativas à expansão e qualificação dos serviços de saúde eram objetos permanentes de cobrança e prestação de contas. 0 processo de implantação da mesa de negociação foi desencadeado no início da gestão e suscitou muito debate, tanto dentro da prefeitura (em particular, com a Secretaria M unicipal da Administração), quanto com os sindicatos dos trabalhadores. Dois anos depois, a mesa foi formalmente implantada.

Todas essas medidas produziram resultados positivos no quediz respeito ao fortalecimento da participação popular: instalou-se um novo Conselho Municipal de Saúde, muito mais ativo, organizaram-se muitos consel hos locais, realizaram-se várias conferências, capacitaram-se os conselheiros.

No que se refere à expansão e melhoria dos serviços, a implantação do Samu foi um êxito. 0 serviço foi reconhecido pela população como a maior realização do governo municipal. No caso do PSF, no entanto, os avanços obtidos, no primeiro ano de gestão, foram progressivamente revertidos, a partir do ano seguinte, pela irregularidade que se instalou nos repasses dos recursos financeiros da Secretaria M unicipal da Fazenda para aSMS.

\section{A dimensão institucional}

Pela nossa vivência, podemos dizer que o gestor é obrigado a dedicar bastante tempo e energia às relações da organização sanitária com outros órgãos. 0 seu desafio é torná-las úteis ao projeto de consolidação do SU S universal.

A estratégia de gestão mais importante, nessa dimensão, é, a partir da identificação dos interesses comuns, distintos e conflitantes existentes entre as instituiç̧ões, fortalecer as relações com os aliados e neutralizar os adversários.

No nível da macrogestão, essa estratégia exige uma análise apurada dos interesses de cada instituição. No nível meso, a organização deve adotar procedimentos que fortaleçam as alianças, colaborando com as instituições que têm interesses comuns. No nível micro, o gestor tem que fazer adaptações nos processos de trabalho, visando a atender às necessidades postas pelas relações interinstitucionais.

Alguns exemplos ajudam a compreender as nuances da estratégia de alianças institucionais capazes de contribuir para aproximar o SUS real do SU S necessário.

No que concerne às instâncias do setor - M inistério e Secretarias da Saúde-, procuramos estabelecer relações cooperativas. Pela própria configuração do SUS, o al cance das metas de saúde depen- 
de da conjunção de esforços das três esferas de governo. Se o gestor adota uma abordagem baseada na boa técnica sanitária, a cooperação tem mais chances de sucesso. Ressalte-se que as opções político-partidárias dos gestores influenciam o tipo de relacionamento que se estabelece. A nossa afinidade política com a direção do M inistério da Saúde se reverteu em forte apoio do nível federal à SMS. M esmo com o gestor estadual, de outra agremiação partidária, foi possível estabelecer relações de colaboração, a partir da ênfase em questões técnicas.

As relações com o Legislativo variam muito. Se os apoiadores são maioria, a situação é mais tranqüila. M esmo uma oposição moderada pode ajudar o gestor, alertando-o, com suas críticas, para os pontos fracos da organização. No nosso caso, enfrentamos uma oposição violenta. Em um primeiro momento, respaldados pelo prefeito, conseguimos estabelecer um diálogo construtivo com os vereadores. Posteriormente, por uma série de fatores, a violência oposicionista intensificou-se, chegando a prejudicar o desempenho da organização, ao impor uma agenda estranha aos objetivos da gestão. Persistimos no diálogo, designando inclusive um assessor parlamentar. Os resultados foram mitigados, com vitórias e derrotas pontuais.

As relações com o Poder Judiciário eo M inistério Público (M P) têm destaque na agenda dos gestores da saúde. Uma legislação generosa como a do SUS oferece larga margem de atuação àqueles que zelam pela aplicação da lei. A rigor, enquanto o SUS não for realmente universal, integral e eqüitativo, juízes e promotores poderão cobrar sempre mais ações. Atéonde não ferem o princípio da razoabilidade, tais cobranças ajudam o gestor. Procuramos construir relações de cooperação com as instituições judiciais. Para isso, tentamos dar transparência às ações da organização, instruindo detalhadamente os processos administrativos. Buscamos atender a todas as solicitações oriundas desses órgãos. E solicitamos, muitas vezes, orientações ou o acompanhamento de processos por parte de técnicos da Justiça ou membros do M P. O resultado foi bastante positivo: instaurou-se, de fato, uma relação de colaboração, com ganhos para todos.

0 relacionamento com a mídia ébastantecomplexo. Em primeiro lugar, os órgãos de comunicação são empresas com interesses comerciais. Em segundo, têm posições ideológicas ou partidárias mais ou menos explícitas. Em terceiro, trabal ham com um objeto - a informação - que requer um tratamento específico para atrair a atenção do público e dos anunciantes. Por diversas razões, os temas da saúde interessam à mídia. Isso pode re- presentar uma oportunidade ou uma ameaça para o gestor. Será uma ameaça, se o gestor menosprezar o papel da comunicação de massa. Para fortalecer o SUS, é preciso formular uma política de comunicação eficiente, que contemple os aspectos comerciais e políticos, tanto quanto os aspectos propriamente jornalísticos. A nossa assessoria de imprensa foi um dos setores da Secretaria quemais trabalhou. Conscientes da relevância da comunicação, enfrentamos uma mídia, em geral, oposicionista e viciada em esquemas clientelistas. Fomos al vos de muitas críticas, freqüentemente baseadas em distorções de fatos ou mesmo em puras invenções, mas conseguimos muitas vezes comunicar ao público a nossa posição.

As relações intragovernamentais também exigem atenção. Há semprea necessidade de articulação com os mais variados órgãos da administração pública. Os processos de elaboração e de execução do orçamento governamental são os exemplos mais claros disso.

$\mathrm{Na}$ nossa experiência, a colaboração com os demais órgãos de governo enfrentou algumas dificuldades. A maior delas decorreu da escassez de recursos frente às demandas por serviços públicos. Em conseqüência, a definição das prioridades foi sempre motivo de conflitos. Uma outra dificuldaderesultou das diferenças nas rotinas de funcionamento dos vários órgãos, o que gerava obstáculos operacionais à cooperação.

Para favorecer a colaboração, tentamos problematizar junto ao prefeito e aos colegas a questão da necessária articulação. Adotamos rotinas organizacionais que envolviam o intercâmbio de informações com outros órgãos. E orientamos nossos subordinados a adotarem posturas colaborativas com os colegas das outras secretarias. Com isso, foi possível manter relações colaborativas com muitos setores da administração municipal ou, ao menos, gerir os conflitos sem desgastes desnecessários.

\section{A dimensão técnico-sanitária}

A dimensão técnico-sanitária relaciona-se ao objetivo de conduzir a organização de acordo com os preceitos técnicos da Saúde Coletiva. Na prática, refere-se às ações de identificação e priorização de problemas de saúdee de proposição e aplicação de soluções. Trata-se da dimensão que confere especificidade à gestão da saúde.

O setor da saúde apresenta particularidades que tornam complexa a tarefa de administrá-lo². Em primeiro lugar, a saúde constitui um valor em 
si mesmo. Em segundo, lida com a diferença entre a ética médica, que orienta a relação singular mé dico-paciente, e a ética administrativa, que rege as decisões administrativas que visam a coletivos de pessoas. Em terceiro lugar, os problemas de saúde são multidimensionais, envolvendo aspectos biológicos, sociais, econômicos, culturais, tecnológicos, etc. E em quarto, o risco da ocorrência de situações de emergência está sempre presente.

A estratégia de fortalecimento da racionalidade técnico-sanitária, para aproximar o SUS possível do SU S necessário, se desdobra em várias ações.

No nível da macrogestão, o desafio é formular políticas e programas de saúde consistentes. A seleção de problemas e respostas é influenciada por fatores de ordem política geral, mas caso se pretenda favorecer a racionalidade técnico-sanitária, não se podenegligenciar o papel das competências próprias dos sanitaristas, (adotamos a seguinte definição de sanitarista, a partir de conceitos elaborados por M endes-Gonçalves ${ }^{3}$, sem limitá-la, todavia, aos médicos: são aqueles trabalhadores, de formação universitária, cujo trabal ho propriamente dito consiste em controlar o processo de trabalho em saúde de todos os trabalhadores da saúde).

Políticas de saúde são respostas, produzidas socialmente e conduzidas pelo aparelho estatal, às necessidades de saúde de toda a população, ainda que não sejam iguais para todos ${ }^{4}$. 0 conceito de política de saúde, na sua acepção mais técnica, re mete à idéia de modelo de atenção à saúde. Por modelo de atenção, entende-se a forma de combinação das tecnologias (conhecimentos, técnicas, equipamentos) disponíveis para atender às demandas ou necessidades de saúde ${ }^{5}$. Se, atualmente, é predominante um modelo biologicista, curativista e individualista, o SU S necessário só se materializará em um modelo de atenção integral, em que sejam oferecidas - considerando-se as necessidades de saúde - tanto as ações curativas e individuais quanto as ações promocionais e preventivas. As díades problema-resposta priorizadas devem, nesse sentido, integrar as ações de promoção e as de assistência.

Na nossa prática, o processo de formulação de políticas foi duplamente interessante: de um lado, pela mobilização dos trabalhadores da saúde e das representações comunitárias; de outro, pelo aportetécnico fornecido pel os sanitaristas da SM S, com 0 apoio de consultorias externas. Assim, conseguimos dar consistência às políticas.

No nível da mesogestão, a dimensão técnicosanitária se realiza nas atividades de planejamento e avaliação. Os planos plurianuais de saúde, as programações e os relatórios de gestão são os ins- trumentos dessas atividades. Esses instrumentos são valiosos como produtos, ou seja, como documentos que dão conhecimento público das ações de saúde eservem deguias para a prática dos membros da organização, mas são também importantes como expressão de um processo que envolve trabalhadores e usuários na proposição das ações de saúde.

As organizações públicas de saúde têm peculiaridades que dificultam adoção de uma racionalidade técnica. Em primeiro lugar, sofrem influência do contexto político, às vezes contrário às concepções do SUS legal. Em segundo, a capacidade de decisão do dirigente é limitada por autoridades externas. Por fim, são obrigadas a seguir normas definidas por outras instâncias ou organizações.

Diante dessas peculiaridades, para incorporar as ações programadas à rotina organizacional, valorizamos as atividades de planejamento e avaliação e adotamos o plano e a programação como guias das práticas da organização, utilizando-os como instrumentos deacompanhamento das ações de saúde, tanto através de seminários específicos, quanto na rotina administrativa.

No nível da microgestão, a dimensão técnicosanitária se apóia nos processos de trabalho dos sanitaristas. A nossa principal tarefa, como gestor, foi a de assegurar aos sanitaristas os meios necessários à execução de seu trabalho, o que incluiu a autorização para circular pelos diversos setores e acompanhar a atuação de todos os colaboradores da SM S.

Dessa forma, várias políticas e programas foram elaborados e bem-sucedidos: o controle da raiva e da tuberculose, a humanização e 0 acolhimento, 0 atendimento às urgências, a saúde da população negra. Houve avanços também nas áreas de saúde mental e saúde bucal.

0 processo dehabilitação do município na gestão plena do sistema de saúde foi conduzido com habilidade e fortaleceu as atividades da regulação, com uma melhor organização do acesso aos serviços especializados e um maior controle sobre os prestadores de serviços.

Por outro lado, a política de expansão do PSF, após certo êxito inicial, fracassou. Certamente, pelas razões já mencionadas das dificuldades financeiras e não por problemas da política em si.

\section{A dimensão administrativa}

A dimensão administrativa senso estrito refere-se ao objetivo de garantir a coordenação da organização. Concretamente, reúne as ações de mobili- 
zação e de uso eficiente dos recursos humanos, financeiros e materiais.

A gestão do trabalho em saúde engloba desdea formulação das políticas de pessoal até as rotinas de trabalho dos funcionários do "setor de recursos humanos", passando pela estrutura de pessoal da organização.

A força de trabalho em saúde representa um nó crítico para a gestão do SUS. Não há uma política de pessoal articulada com as políticas de saúde. São insuficientes a quantidade e a qualificação de profissionais na rede pública. Em uma mesma organização, coexistem diferentes jornadas, salários e vínculos de trabalho. Ademais, as condições de trabalho são, em geral, precárias. 0 resultado é a desmotivação e o descompromisso de muitos trabalhadores para com o SUS.

Aqui, a estratégia central para aproximar o SUS possível do SUS necessário éformular uma política de gestão do trabalho coerente com as políticas de saúde.

No nível macro, é preciso articular todos os interessados na questão para discutir uma política de pessoal, identificando o perfil da mão-de-obra necessária, em quantidade equalidade, para alcançar os objetivos das políticas de saúde.

Deve-se ter em conta que os interesses envolvidos são numerosos, às vezes contraditórios, e exigem um complexo processo de negociação. Conduzir o processo de elaboração da política de forma transparente éa melhor tática, pois ajuda a esvaziar as pressões a favor de interesses ilegítimos.

Na nossa experiência, desencadeamos um processo bastante participativo de discussão sobre a política de pessoal, envolvendo os consel heiros de saúde, os sindicatos dos trabal hadores e as secretarias sistêmicas da prefeitura municipal - Administração, Fazenda e Governo.

N o nível da mesogestão, émister ampliar equalificar o quadro de pessoal, assim como implantar planos decargos, carreiras evencimentos. Além disso, todo esforço deve ser feito para oferecer condições adequadas de trabalho, com salários compatíveis com a realidade do mercado e com um ambiente e instrumentos de trabalho apropriados.

Convocamos mais de 500 profissionais concursados, de diversas categorias, e intensificamos as atividades de capacitação. Elaboramos ainda um novo plano de cargos, carreiras e vencimentos. $\mathrm{No}$ primeiro ano da gestão, convencemos o prefeito a conceder um aumento de $50 \%$ nos salários de todos os colaboradores da SMS, sendo $35 \%$ a título deincentivo ao desempenho.

No nível micro, o gestor deve ter mecanismos de acompanhamento do trabalho profissional. As ações de saúde, para serem efetivas, precisam estar lastreadas em competências que são inerentes às atividades dos profissionais. Nesse sentido, favorecer a autonomia profissional é fundamental. No entanto, sem o devido acompanhamento, não há como assegurar a coerência entre essas atividades e os objetivos da política de saúde ou da organização ${ }^{6}$. Para acompanhar o trabalho profissional, implantamos um sistema de avaliação, que considerava tanto 0 desempenho individual, quanto 0 coletivo (da UnidadedeSaúde). Os critérios deavaliação remetiam à implantação da política de humanização e ao fortalecimento do programa de controle da tuberculose. E o resultado da avaliação condicionava o recebimento do incentivo salarial.

Enfim, podemos dizer que iniciamos uma política de valorização dos trabalhadores da saúde. Infelizmente, a implantação do plano de cargos ea realização do concurso foram barradas pelas dificuldades financeiras da prefeitura, decorrentes, em parte, das opções políticas do chefe do governo.

Q uanto à gestão financeira, nesse momento, a principal estratégia é assegurar um fluxo regular de recursos para a saúde nos patamares mínimos estabelecidos pela emenda constitucional $n=29$.

No nível da macrogestão, a ação mais importante élutar pela regulamentação em lei da EC-29. o SUS precisa, no curtíssimo prazo, de um aumento de recursos financeiros. Como membro do Conselho Nacional de Secretarias Municipais de Saúde (Conasems), envolvemo-nos diretamente no processo de mobilização política junto ao Congresso Nacional pela aprovação do projeto de lei 01/2003, que regulamentava a EC- 29.

No nível meso, a organização de saúde deve ter autonomia para gerir os recursos. Trata-se, evidentemente, de uma disputa por poder, dentro da estrutura do governo. A transferência automática de recursos para a saúde significa uma redução da margem de liberdade do gestor financeiro. Todavia, não se pode desrespeitar a determinação política de priorizar a saúde, expressa na EC-29, mesmo que implique a limitação do poder de decisão dos gestores financeiros - e dos chefes do Executivo - quanto às prioridades de governo.

$\mathrm{Na}$ prática, tivemos aqui a nossa maior dificuldade. A Secretaria Municipal da Fazenda (Sefaz) nunca aceitou realizar repasses automáticos para o Fundo M unicipal da Saúdee conseguiu fazer prevalecer seu ponto de vista junto ao prefeito. Pior: quando as dificuldades financeiras se acentuaram, com as despesas correntes superando as receitas, a Sefaz não hesitou em atrasar os pagamentos das contas da Saúde.

No nível da microgestão, o desafio é conseguir 
quea área financeiro-administrativa e a área técnica trabalhem demaneira coordenada. Alcançar um nível ótimo de coordenação não ésimples, pois as lógicas de trabalho das duas áreas são distintas. Como tática, vale aproximar os técnicos para que entendam os trabalhos uns dos outros. Uma programação feita de forma participativa e a existência de mecanismos coletivos de acompanhamento das ações também ajudam. Efetivamente, a nossa diretriz nesse sentido foi cumprida e houve uma verdadeira aproximação entre as duas áreas. Talvez, paradoxalmente, as dificuldades financeiras tenham contribuído para isso.

A gestão de recursos materiais, por sua vez, envolve as atividades relacionadas à aquisição, à conservação e ao uso apropriado de imóveis, equipamentos, veículos e insumos.

Aqui, a estratégia geral éval orizar o conceito de eficiência dentro da organização.

No nível macro, épreciso formular uma política de gestão de materiais. 0 grau de centralização dos processos de aquisição e de manutenção e a opção pela organização própria ou pela terceirização dos serviços de apoio são decisões fundamentais a serem tomadas com base em considerações financeiras e em estilos de gestão.

No caso do nosso município, encontramosum alto grau de centralização, em mãos da Secretaria da Administração, e uma elevada proporção de serviços terceirizados. $\mathrm{Na}$ busca de maior autonomia para a SM S, conseguimos descentralizar a gestão de recursos típicos da saúde, como os medicamentos. Quanto à terceirização, houveuma política geral da prefeitura de reforçar a administração direta, através da contratação de pessoal concursado (houve também a criação da guarda municipal, mas que não chegou a ser implantada). Foram iniciativas que, no caso concreto, melhoraram a eficiência da gestão municipal.

No nível da mesogestão, a principal tarefa do gestor refere-se à definição dos fluxos dos processos administrativos entre os vários setores da instituição. A importância de uma definição correta dos fluxos não é pequena: o grau de fluidez dos processos é determinante do nível de eficiência da organização.

Discutimos bastante a questão dos fluxos, até decidimo-nos por uma alternativa. Não conseguimos, no entanto, obter o consenso suficiente para quetodos aderissem ao modelo escolhido. Ao contrário, estabeleceu-se uma disputa interna pelo controle dos processos administrativos. As tentativas de resolução do conflito, através da definição precisa de atribuições para cada setor, não foram bem sucedidas. Talvez medidas mais profundas, com a substituição de assessores, devessem ter sido tomadas. 0 fato é que a eficiência da organização foi comprometida.

No nível micro, a gestão de materiais exige a articulação dos processos de trabalho da área administrativa com aqueles das áreas técnicas, haja vista a dependência mútua entre ambas. Um problema comum é a falta de práticas regulares de planejamento e avaliação das atividades administrativas típicas. Torná-las regularesé, portanto, uma tarefa do gestor.

A nossa área administrativa aproximou-se das áreas técnicas e adotou, concretamente, práticas deplanejamento eavaliação desuas atividades próprias. Com isso, conseguiu melhorar seu desempenho. Entretanto, os conflitos acima referidose 0 acúmulo progressivo de dificuldades financeiras acabaram por impor ao setor uma rotina de enfrentamento de crises que, em certa medida, fez retroceder a melhoria al cançada.

\section{Comentáriosfinais}

A implantação do SUS universal, integral e eqüitativo depende de mudanças sociais que extrapolam o espaço de governabilidade dos gestores da saúde. Isso não diminui, no entanto, a importância do papel desses agentes.

De fato, a gestão das organizações de saúde faz parte da luta política pelo SUS. Nesse sentido, as estratégias de gestão, adotadas por partidários do SUS, podem ser mais ou menos facilitadoras do seu avanço.

A partir deuma experiência prática, vivenciada por alguém com formação especializada em Saúde Coletiva, durantedois anos emeio, em uma Secretaria da Saúde de um município de grande porte, foram apresentadas estratégias de gestão que visavam contribuir para a efetivação de um sistema de saúde universal.

Como se viu, houve êxitos efracassos, avanços e recuos. $N$ ão se tratou, no entanto, de uma avaliação sistemática da nossa gestão. Tratou-se apenas de uma tentativa de ressaltar a importância ea complexidade da formulação deestratégias degestão das organizações públicas de saúde, na luta pela efetivação do SUS.

Esperamos que esta apresentação possa contribuir para o debate sobre a gestão institucional da saúde, tão necessário quanto o debate nos planos ideológico ou econômico. 


\section{Referências}

1. Garcia GG. Las reformas de salud y los modelos de gestión. Revista Panamericana de Salud 2001; 9(6):406412.

2. Dussault G, Souza LE. Gestão estratégica de recursos humanos. 2000. [M imeo]

3. M endes-Gonçalves RB. Tecnologia e organização social das práticas de saúde. Características tecnológicas de processo de trabalho na rede estadual de centros de saúde de São Paulo. São Paulo: Hucitec; Rio de Janeiro: Abrasco; 1994

4. Eibenschultz C. Estado y política sanitaria. Aproximación teórica metodológica. In: Fleury-Teixeira S. (organizador) Estado y políticas sociales em América Latina. Ciudad de M éxico:Universidad Autônoma Metropolitana; Rio de Janeiro: Fiocruz; 1992. p. 51-78.

5. Paim J. Atenção à saúde no Brasil. In: Paim J. Desafios para a Saúde Coletiva no século XXI. Salvador: Edufba; 2006. p. 11-47.

6. Mintzberg H. A burocracia profissional. In: Mintzberg $\mathrm{H}$. Criando organizações eficazes: estruturas em cinco configurações. São Paulo: Atlas; 1995. p.189-212.

Artigo apresentado em 24/09/2007

Aprovado em 03/12/2007 